\section{QUAIS AS TENDÊNCIAS QUE AS \\ PESQUISAS SOBRE $O$ \\ CURRÍCULO INTEGRADO DA \\ EDUCAÇÃO PROFISSIONAL \\ REVELAM?}

WHAT ARE THE TRENDS THAT

RESEARCH ON THE

INTEGRATED CURRICULUM OF

PROFESSIONAL EDUCATION

REVEAL?

\section{¿CUÁLES SON LAS TENDENCIAS}

\section{QUE DESVELA LA}

INVESTIGACIÓN SOBRE EL

CURRÍCULO INTEGRADO DE

EDUCACIÓN PROFESIONAL?

Resumo: $O$ artigo discute o currículo integrado no âmbito da Educação Profissional no Brasil. Configurando-se como uma pesquisa exploratória e bibliográfica, utilizamos como metodologia o Mapeamento Sistemático para realizar um levantamento dos artigos científicos sobre essa temática publicados entre os anos de 2009 e 2019 e disponibilizados no Portal de Periódicos da CAPES. A pesquisa foi realizada no período de fevereiro a abril de 2019, como parte dos estudos realizados no Mestrado em Educação Profissional e Tecnológica do IFMA Campus São Luís/Monte Castelo, tendo como objetivo identificar para qual direção apontam os estudos sobre currículo integrado no âmbito da Educação Profissional no Brasil. Inicialmente apresentamos um breve aporte teórico sobre a concepção de Currículo Integrado, passando pela análise qualitativa e quantitativa dos dados encontrados no Mapeamento, para chegarmos à conclusão de quais são as tendências que as pesquisas sobre Currículo Integrado no Brasil revelam.

Palavras-chave: Currículo Integrado. Educação Profissional. Mapeamento Sistemático.

Recebido em: 16/09/2019

Aceito em: 29/05/2020

Publicação em: 31/07/2021
Luciana de Sousa Alves da Silva Mestre em Educação Profissional e Tecnológica

Universidade Federal do Maranhão, Brasil.

E-mail: lucialves1512@gmail.com

Orcid: https://orcid.org/0000-0003-11247642

Alberes de Siqueira Cavalcanti

Doutor em Educação em Ciências e Matemática

Professor do Instituto Federal do Maranhão, Brasil.

E-mail: alberes@ifma.edu.br

Orcid: https://orcid.org/0000-0001-75369679

Como citar este artigo:

SILVA, L. S. A.; CAVALCANTI, A. S. QUAIS AS TENDÊNCIAS QUE AS PESQUISAS SOBRE O CURRÍCULO INTEGRADO DA EDUCAÇÃO PROFISSIONAL REVELAM?. Revista Espaço do Currículo, v. 14, n. 2, p. 1-13, 2021. ISSN1983-1579.

DOI: https://doi.org/10.22478/ufpb.1983-

$1579.2021 \mathrm{~V} 14 \mathrm{n} 2.45925$. 
Abstract: The article discusses the Integrated Curriculum in the scope of Professional Education in Brazil. Configuring as an exploratory and bibliographic research, we used as methodology the Systematic Mapping to carry out a survey of the scientific articles on this subject published between 2009 and 2019 and made available in CAPES's Portal of Periodicals. The research was carried out from February to April 2019, as part of the studies carried out in the Master in Professional and Technological Education of IFMA Campus São Luís/Monte Castelo, aiming to identify the direction of studies on Integrated Curriculum in the scope of Professional Education in Brazil. Initially we present a brief theoretical contribution on the conception of Integrated Curriculum, through the qualitative and quantitative analysis of the data found in the Mapping, to find out what the trends are that the research on Integrated Curriculum in Brazil reveals.

Keywords: Integrated Curriculum; Professional Education; Systematic Mapping.

Resumem: El artículo analiza el currículo integrado en el ámbito de la Educación Profesional en Brasil. Como investigación exploratoria y bibliográfica, utilizamos el Mapeo Sistemático como metodología para realizar un relevamiento de artículos científicos sobre este tema publicados entre 2009 y 2019 y disponibles en el Portal de Revistas CAPES. La investigación se realizó de febrero a abril de 2019, como parte de los estudios realizados en la Maestría en Educación Profesional y Tecnológica en el IFMA Campus São Luís/Monte Castelo, con el objetivo de identificar en qué dirección los estudios sobre currículo integrado dentro del alcance de la Educación Profesional en Brasil. Inicialmente, presentamos un breve aporte teórico sobre el concepto de Currículo Integrado, pasando por el análisis cualitativo y cuantitativo de los datos encontrados en el Mapeo, para llegar a la conclusión de las tendencias que revela la investigación sobre Currículo Integrado en Brasil.

Palabras clave: Plan de estudios integrado; Educación profesional; Mapeo sistemático.

\section{INTRODUÇÃO}

No bojo das discussões que culminaram nas reformas educacionais implementadas pelo governo federal na década de 90 do século XX, educadores progressistas defendiam a implantação de uma formação escolar que superasse a histórica dualidade entre educação geral e formação profissional, possibilitando o acesso de todos a condições dignas para o exercício consciente da cidadania, a inserção no mundo do trabalho e o prosseguimento nos estudos.

Dessas discussões, a concepção que prevaleceu na década de 1990 foi a que separava obrigatoriamente o Ensino Médio da Educação Profissional, materializada no Decreto $n^{\circ} 2.208$, publicado em abril de 1997. A partir deste dispositivo legal,

o ensino médio retoma legalmente um sentido puramente propedêutico, enquanto os cursos técnicos, agora obrigatoriamente separados do ensino médio, passam a ser oferecidos de duas formas. Uma delas é a Concomitante ao ensino médio. [...] A outra forma é a Subsequente, destinada a quem já concluiu o ensino médio e, portanto, a educação básica (MOURA, 2007, p. 16-17).

Mais uma vez, a mobilização por uma educação pública de qualidade perdia espaço para os interesses do capital, tendo sido adiada a discussão sobre a integração no ensino de nível médio. Essa discussão seria retomada apenas na década seguinte, no período que antecedeu a publicação do Decreto $\mathrm{n}^{\circ}$ 5.154, de 23 de julho de 2004, que além de revogar integralmente o Decreto anterior, trazia a possibilidade de integração do Ensino Médio com a Educação Profissional.

Mesmo mantendo as formas concomitante e subsequente, este novo Decreto teve o mérito de abrir caminho para a integração no nível médio, que deveria ocorrer através de matrícula única e na mesma instituição de ensino, por meio da integração entre formação geral e formação técnica, conduzindo o aluno à habilitação profissional técnica de nível médio (BRASIL, 2004).

A partir de então, reacende-se a discussão sobre a educação politécnica, concebida por Marx (1994) como o germe da educação do futuro, capaz de associar educação intelectual, física e instrução politécnica ao trabalho produtivo, configurando-se no único meio de produzir seres humanos 
integralmente desenvolvidos.

Esta formação humana integral, obtida por meio da associação entre educação e trabalho, que "busca garantir ao adolescente, ao jovem e ao adulto trabalhador o direito a uma formação completa para a leitura do mundo e para atuação como cidadão pertencente a um país, integrado dignamente à sua sociedade política" (FRIGOTTO; CIAVATTA; RAMOS, 2005, p. 85), está na base da concepção de currículo integrado.

Deste modo, essa nova forma de fazer currículo ultrapassa a visão reducionista que considerava o currículo tradicional como sinônimo de "grade curricular", definida por Estivalete (2016, p. 40) como "uma listagem de disciplinas isoladas em seus campos de conhecimento específicos". A partir do currículo integrado, busca-se superar a fragmentação do conhecimento e a especialização excessiva, visando integrar os saberes escolares através de um diálogo interdisciplinar permanente entre as diversas áreas do conhecimento.

É sobre esta concepção de Currículo Integrado que trataremos neste artigo, que resulta de uma pesquisa exploratória e bibliográfica realizada no período de fevereiro a abril de 2019, como parte dos estudos realizados no Mestrado em Educação Profissional e Tecnológica do IFMA Campus São Luís/Monte Castelo. Com o objetivo de identificar para qual direção apontam os estudos sobre currículo integrado no âmbito da Educação Profissional no Brasil, nos propomos a realizar um levantamento dos artigos científicos publicados sobre essa temática entre os anos de 2009 e 2019, e disponibilizados no Portal de Periódicos da CAPES. Para isso, utilizamos a metodologia do Mapeamento Sistemático.

Inicialmente, esboçamos um breve aporte teórico sobre a concepção de currículo integrado, para em seguida, explicitarmos a metodologia utilizada, momento no qual apresentaremos os resultados encontrados no Mapeamento, fazendo uso de métodos quantitativos e qualitativos de análise dos dados; para ao final, apontarmos os rumos pelos quais estão seguindo as pesquisas sobre currículo integrado no Brasil.

\section{CURRÍCULO INTEGRADO: superando a dicotomia e a fragmentação curricular}

A possibilidade de integração entre as disciplinas de caráter propedêutico e as disciplinas técnicas assenta-se no ideal progressista de rompimento da dualidade entre formação para a vida e formação para o trabalho. Dualidade esta que, historicamente, fragmenta o ensino e contribui para a desigualdade na formação das elites e da classe trabalhadora.

Ao propor uma ruptura com a lógica disciplinar, o currículo integrado contribui para romper as fronteiras invisíveis entre as disciplinas, além de "evitar a reprodução de ideologias do estado regulador e representante do pensamento hegemônico, aliada à coibição do processo de alienação do indivíduo" (ESTIVALETE, 2016, p. 39).

A capacidade que o currículo integrado possui de formar profissionais críticos, capazes de reconhecer sua condição social, refletir sobre o contexto sócio-político e lutar em favor dos interesses coletivos, é a característica que o diferencia das formas de organização curricular tradicional, vinculadas aos interesses do mercado (AZEVEDO; SILVA; MEDEIROS, 2015). Outro diferencial é que

o currículo integrado instiga o aluno a buscar a solução do problema apresentado, enquanto o currículo tradicional apresenta as teorias e somente depois disso aponta os questionamentos sobre o tema, tendo o aluno já recebido as soluções sem ter refletido sobre o assunto. Nesse sentido, a prática de integração consegue articular os saberes, unir as partes no todo e o todo nas partes, superando a fragmentação (RODRIGUES; ARAÚJO, 2017, p. 18).

Logo, uma proposta de organização curricular integrada deve buscar recompor a totalidade do conhecimento que as disciplinas escolares compartimentalizaram ao longo dos séculos, ao promover uma hierarquização dos saberes em obediência "à lógica fragmentar, própria da racionalidade produzida nas sociedades capitalistas" (AMADO, 2015, p. 414).

Conforme esclarece Ciavatta (2005, p. 85), 
a ideia de formação integrada sugere superar o ser humano dividido historicamente pela separação social do trabalho entre ação de executar e a ação de pensar, dirigir ou planejar. Trata-se de superar a redução da preparação para o trabalho ao seu aspecto operacional, simplificado, escoimado dos conhecimentos que estão na sua gênese científico-tecnológica e na sua apropriação histórico-social.

Na perspectiva da construção do conhecimento como uma totalidade, a proposta de integração do Ensino Médio à Educação Profissional deve ter como premissa a união indissociável entre teoria e prática, por meio do diálogo interdisciplinar entre os conhecimentos científicos, tecnológicos, sociais e culturais e as habilidades necessárias ao desempenho de profissões técnicas, que devem estar imbricados desde o início do curso e contemplados de forma equânime no currículo.

Desse modo, o sentido de um currículo integrado vai além da mera justaposição ou somatório dos conhecimentos disciplinares uns aos outros, mas implica em "assumir uma postura epistemológica, assentada nos princípios da interdisciplinaridade, da contextualização e na visão totalizante da realidade, de forma a resgatar a ciência na sua inteireza, assumindo um caráter transformador" (PEDROSA, 2016, p. 181).

O princípio da interdisciplinaridade no currículo integrado, não se resume a uma simples articulação de conteúdos de diferentes disciplinas, nem à prática pedagógica que reúne mais de um professor numa mesma atividade, pois ela não possui a intenção de diluir ou de anular a contribuição de cada disciplina, mas sim de promover o diálogo e a interação recíproca entre os domínios do saber, o que impede o estabelecimento da supremacia de uma ciência sobre outra igualmente importante.

Porém, por mais que muitas vezes se confunda interdisciplinaridade com integração, elas não são sinônimas. Fazenda (2011), esclarece que a interdisciplinaridade é fator de transformação e de mudança social, enquanto a integração pode ser fator de estagnação e manutenção do status quo, se for utilizada como um fim em si mesma. Ao mesmo tempo, a autora reconhece que ambas estão interligadas num processo de diálogo permanente.

Como outro princípio do currículo integrado, a contextualização compreende uma estratégia de problematização do contexto social, histórico, econômico e político, que fazem parte do cotidiano do aluno e conferem sentido à relação estabelecida entre o conhecimento científico e o conhecimento da experiência, dando vida ao conteúdo escolar e tornando significativa a aprendizagem (MOURA, 2007).

Para Santos, Nunes e Viana (2017, p. 166),

somente através da contextualização é possível despertar o interesse do estudante, bem como trazer sentido para a aprendizagem, tornando o processo educativo mais prazeroso, visto que este passa a ter relação com a vida cotidiana do educando ou com seus conhecimentos anteriormente adquiridos.

Assim, um currículo integrado que se quer comprometido com a construção de um projeto de transformação social que possibilite aos estudantes refletir e atuar sobre a sua realidade social e política, deve ser construído tendo como base a indissociabilidade entre os saberes gerais e específicos, a união entre teoria e prática, e o trabalho como princípio educativo.

Conforme orientam Azevedo, Silva e Medeiros (2015, p. 84), "considerar o trabalho como princípio educativo equivale a dizer que o ser humano é produtor de sua realidade e, por isto, dela se apropria e pode transformá-la. Equivale a dizer, ainda, que é sujeito de sua história e de sua realidade". E assim como o trabalho, base da existência humana, as dimensões fundamentais da ciência, da tecnologia e da cultura, que estruturam a prática social, devem orientar todo o processo educativo no âmbito do currículo integrado.

Entretanto, Santomé (1998) alerta para que a construção do currículo integrado não se traduza num mero slogan, caso contrário, estará favorecendo os interesses hegemônicos ao preparar os estudantes para assumirem posições dominantes ou subordinadas na sociedade, interesse contra os 
quais essa proposta é dirigida.

E o currículo também não é um conceito abstrato que existe separadamente da existência humana, mas antes de tudo, uma construção cultural, sendo definido por Sacristán (2000, p. 34) como "o projeto seletivo de cultura, cultural, social, política e administrativamente condicionado, que preenche a atividade escolar e que se torna realidade dentro das condições da escola tal como se acha configurada".

De forma semelhante, Saviani (1998, p. 33) observa que para elaborar um currículo, deve ser realizada uma "seleção de elementos da cultura, passíveis (e desejáveis) de serem ensinados/aprendidos na educação escolar", e nele devem estar inclusas as matérias de ensino, suas distribuições pelos níveis escolares, suas formas de avaliação e sua carga horária.

Porém, o que se espera de um currículo integrado é mais do que um programa de estudos ou o vocabulário de um curso. Espera-se que a partir dele seja introduzida uma inovação na concepção de Ensino Médio que atenda aos interesses sociais dos sujeitos aos quais se destina, visando construir um saber globalizado.

Desta forma, esperamos que, pela análise das produções acadêmico-científicas publicadas sobre o currículo integrado no âmbito da Educação Profissional, possamos identificar uma direção comum que conduza a uma concepção de currículo realmente inovadora e comprometida com o ideal de formação humana integral que está na base da proposta do Ensino Médio Integrado.

\section{O MAPEAMENTO SISTEMÁTICO}

A metodologia utilizada na construção deste artigo foi a do Mapeamento Sistemático, descrita por Rocha, Nascimento e Nascimento (2018) como uma técnica de pesquisa que, por meio do levantamento da literatura sobre um determinado tema, permite delinear uma trajetória de ideias que conduzem à geração de hipóteses provenientes das evidências encontradas, que poderão ser confirmadas ou refutadas posteriormente, dando origem a novas pesquisas.

Conforme descrito inicialmente, nossa temática é sobre o currículo integrado no âmbito da Educação Profissional no Brasil. Diante disto, definimos como universo de pesquisa, os artigos científicos publicados pela comunidade acadêmica em periódicos revisados por pares e disponíveis no Portal de Periódicos da CAPES ${ }^{1}$. Dentro deste Portal, realizamos uma busca por assunto, utilizando as palavraschave "currículo integrado" e "educação profissional", e aplicando o filtro "data de publicação", onde foi selecionado o intervalo de anos de 2009 a 2019.

Considerando o modelo de Mapeamento Sistemático realizado pelos autores Bonfim et. al. (2019), durante a etapa inicial de aplicação desta técnica, faz-se necessário a elaboração de um protocolo onde devem ser estabelecidas as regras para a obtenção de resultados fidedignos.

Quadro 1 - Protocolo do Mapeamento Sistemático

\begin{tabular}{||l|l||}
\hline \hline Objetivo & $\begin{array}{l}\text { Identificar para qual direção apontam os estudos sobre currículo integrado no } \\
\text { âmbito da Educação Profissional no Brasil. }\end{array}$ \\
\hline Questão Central & $\begin{array}{l}\text { Para qual direção apontam as temáticas mais recorrentes nas produções } \\
\text { acadêmicas sobre o currículo integrado no âmbito da Educação Profissional } \\
\text { no Brasil? }\end{array}$ \\
\hline Seleção da Base de Dados & Portal de Periódicos da CAPES. \\
\hline Critérios de Inclusão & $\begin{array}{l}\text { Artigos completos; artigos no idioma português; artigos publicados entre os } \\
\text { anos de 2009 e 2019; artigos que abordam a temática do currículo integrado } \\
\text { no âmbito da Educação Profissional. }\end{array}$ \\
\hline Critérios de Exclusão & $\begin{array}{l}\text { Artigos duplicados; artigos em idioma estrangeiro; artigos que abordam o } \\
\text { Currículo integrado em contexto diverso da Educação Profissional; artigos que } \\
\text { abordam somente a Educação Profissional, sem considerar o currículo } \\
\text { integrado. }\end{array}$ \\
\hline Strings de busca & Currículo integrado; Educação Profissional. \\
\hline
\end{tabular}

\footnotetext{
${ }^{1}$ Disponível no endereço eletrônico: http://www.periodicos.capes.gov.br/ Acesso em: 09/04/2019.
} 
Fonte: Adaptado de Bonfim et. al. (2019)

Durante a etapa inicial de execução do Mapeamento, encontramos na busca de estudos primários um total de sessenta e cinco artigos. A partir desse quantitativo, procedemos à etapa seguinte com a leitura do título, resumo e palavras-chave para aplicarmos os critérios de inclusão e exclusão, conforme definidos no protocolo. Após a aplicação desses critérios foram excluídos:

- 1 artigo publicado em 2005;

- 5 artigos em duplicidade;

- 12 artigos em idioma estrangeiro;

- 2 artigos que tratam do currículo integrado no contexto do Ensino Superior;

- 1 artigo que trata do currículo integrado na Educação Básica;

- 27 artigos que tratam da Educação Profissional, mas não abordam questões relativas ao currículo integrado.

Após esta seleção, restaram dezessete artigos a serem analisados na última etapa do Mapeamento. Nestes, foram realizadas leituras completas e extraídas informações referentes às temáticas principais, universo da investigação, procedimentos técnico-metodológicos, ano de publicação, formação acadêmica dos autores e os teóricos mais citados. Estas informações extraídas da leitura dos artigos, irão compor as categorias de análise do nosso Mapeamento.

A primeira categoria diz respeito à temática principal dos artigos analisados. Conforme o Gráfico 1, o maior percentual (36\%) ficou com os artigos que abordam a integração curricular na Educação Profissional, tema que aparece em nove publicações. Com uma quantidade bem próxima, aparece a temática do PROEJA com oito artigos, o que representa 32\% do total. Em seguida aparece a temática do Ensino Integrado com quatro artigos que representam $16 \%$ do total, sendo que destes, um artigo aborda o ensino de Ciências da Natureza e Matemática, e dois artigos tratam do ensino da Matemática. Em menor número, aparecem as temáticas dos Institutos Federais de Educação (8\%) com dois artigos apenas; do Protagonismo Juvenil (4\%) e do Trabalho Docente (4\%), estes dois últimos com apenas um artigo cada.

Gráfico 1 - Temáticas Principais

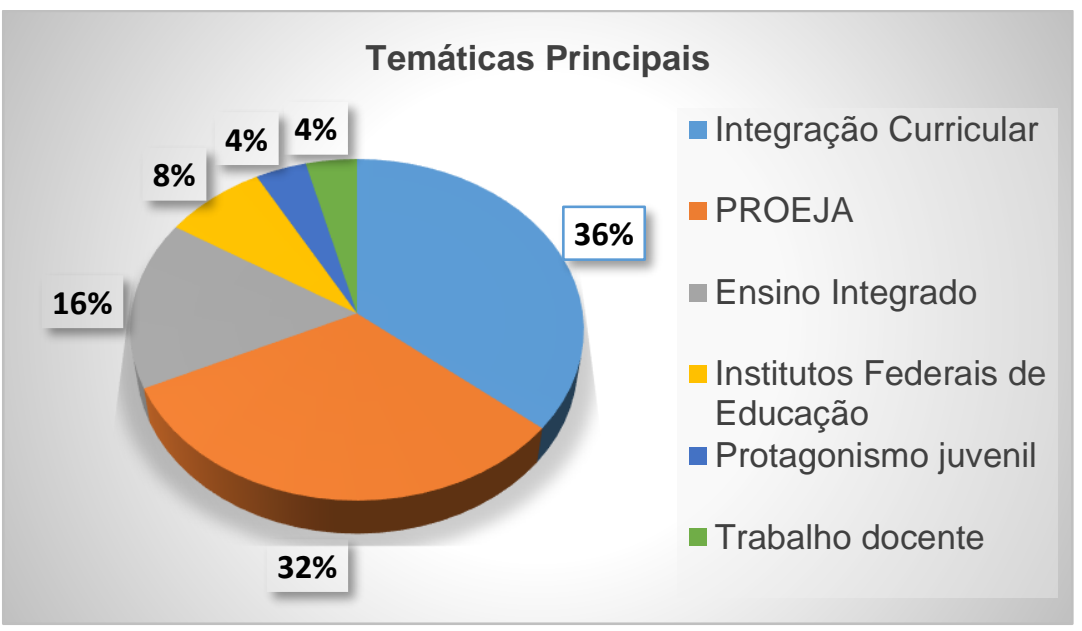

Fonte: Elaborado pelos autores. São Luís, 2019.

A temática da integração curricular aparece nos artigos de Estivalete (2016); Rodrigues e Araújo (2016); Moreira e Gobbi (2011); e Santos (2012) como um ideal de prática pedagógica que deve ser alcançado, por possibilitar uma legítima integração de saberes através do currículo. Enquanto Estivalete (2016) busca mapear o interesse da comunidade acadêmica sobre pesquisas envolvendo o currículo integrado, Rodrigues e Araújo (2016) se preocupam em investigar a concepção dos docentes sobre suas próprias práticas de integração curricular. 
Os artigos de Santos (2012) e Moreira e Gobbi (2011) trazem uma reflexão sobre duas experiências de organização do currículo integrado na Educação Profissional Técnica de Nível Médio; o primeiro tem como contexto o Instituto Federal de Brasília e apresenta uma sugestão de proposta curricular a ser desenvolvida nos diversos campi daquele IF; o segundo traz o relato do desafio experienciado pelos autores durante o processo de implantação do currículo integrado no Instituto Federal do Triângulo Mineiro - IFTM.

Também fazendo parte da temática da integração curricular, o artigo de Santos, Santos, Professor e Silva (2018) apresenta um estudo sobre práticas pedagógicas integradoras compartilhadas por outros autores em suas publicações científicas, que possam contribuir para a implementação do currículo integrado e para a formação dos sujeitos do processo de ensino-aprendizagem.

Tivemos ainda, casos de artigos que por sua temática ampla, foram inseridos em mais de uma categoria. É o caso dos artigos de Silva (2011); Sales e Reis (2019); Amado (2015); Viriato, Favoreto e Klein (2012), que discutem a integração curricular em cursos do Programa de Integração da Educação Profissional Técnica de Nível Médio na Modalidade de Educação de Jovens e Adultos - PROEJA, aparecendo nas duas principais temáticas.

Silva (2011) discute em seu artigo a política curricular de integração entre formação profissional e formação básica expressa nos documentos normativos do PROEJA, a partir das interpretações dos sujeitos sobre as propostas de currículo integrado e do trabalho como princípio educativo. De forma semelhante, o artigo de Sales e Reis (2019) analisa como as diversas concepções de integração expressas por gestores e professores do PROEJA se convertem em currículos integrados de formatos e configurações distintas.

Por sua vez, Amado (2015) analisa a forma como a educação organiza seus espaços, práticas e relações de modo a ultrapassar velhos discursos de adaptação de práticas tida como regulares às especificidades da Educação de Jovens e Adultos, além de evidenciar o potencial de transformação presente no currículo integrado.

As autoras Viriato, Favoreto e Klein (2012), além de trazerem as temáticas da integração curricular e do PROEJA, discutem também o trabalho docente, sendo, portanto, o único artigo representante de três temáticas diferentes em nosso Mapeamento. Nele, as autoras debatem o currículo escolar na perspectiva da complexidade, iniciando pela discussão da política educacional da Educação de Jovens e Adultos, passando pela organização dos conteúdos ministrados nos cursos do PROEJA e chegando aos desafios encontrados pelos professores para a implantação efetiva do currículo integrado.

Além destes, a temática do PROEJA aparece ainda nos artigos de Silva (2013); Silva e Sá (2016); Pedrosa (2016); e Miranda e Fonseca (2017). O artigo de Silva (2013) apresenta os avanços, percalços e obstáculos das pesquisas sobre currículo da Educação Profissional Integrada à Educação de Jovens e Adultos, bem como as questões que ficaram em aberto, e que, portanto, podem dar origem a novas pesquisas.

Já os autores Silva e Sá (2016), analisam a materialização da proposta curricular de um curso integrado de Educação Profissional à Educação de Jovens e Adultos no âmbito do PROEJA, pela ótica dos seus estudantes. Também tomando como critério de análise a perspectiva dos estudantes jovens e adultos do PROEJA, Miranda e Fonseca (2017) analisam a forma como eles compreendem e interagem diante de tentativas de integração entre o currículo de Matemática e a vida profissional.

O artigo de Miranda e Fonseca (2017), bem como o de Pedrosa (2016) abordam também duas temáticas: o PROEJA e o ensino integrado. E possuem mais um ponto em comum, o ensino de Matemática, tratado por Pedrosa (2016) juntamente com o ensino de Ciências da Natureza. Nele, a autora discute as concepções dos sujeitos envolvidos no ensino dessas duas áreas do conhecimento, identificando as aproximações e distanciamentos da proposta de fazer currículo integrado na Educação de Jovens e Adultos.

A categoria do ensino integrado conta ainda com dois outros artigos: o de Santos, Nunes e Viana (2017), que explora a relação entre o conceito de currículo e as metodologias do ensino de Matemática, 
destacando a importância de realização de um processo formativo baseado numa abordagem contextualizada e interdisciplinar; e o artigo de Castaman e Hannecker (2017), onde as autoras fazem uma reflexão sobre o ensino integrado no contexto dos Institutos Federais de Educação, apresentando experiências de práticas pedagógicas exitosas, bem como de resistências que dificultam o processo de integração curricular.

O artigo de Castaman e Hannecker (2017) também perpassa por duas temáticas: a do ensino integrado e a dos Institutos Federais de Educação, sendo que esta última aparece ainda no artigo de Zatti (2016). Esse autor analisa em seu artigo se a proposta de educação dos Institutos Federais está configurando um novo paradigma em Educação Profissional e Tecnológica que supere o viés tecnicista e seja baseado no conceito de emancipação.

Representando sozinho a temática do protagonismo juvenil, o artigo de Azevedo, Silva e Medeiros (2015) discute o currículo integrado na Educação Profissional enquanto espaço privilegiado de desenvolvimento do protagonismo juvenil, característica essencial para uma formação humana omnilateral e emancipadora que contribua para o alcance dos interesses sociais coletivos.

A segunda categoria de nosso Mapeamento diz respeito ao universo da investigação dos artigos analisados. Pela análise do Gráfico 2, percebemos que oito artigos, quase a metade do total analisado, tiveram seu universo de investigação centrado em um dos Institutos Federais de Educação, Ciência e Tecnologia (IF's) espalhados pelo Brasil.

Gráfico 2 - Universo da investigação

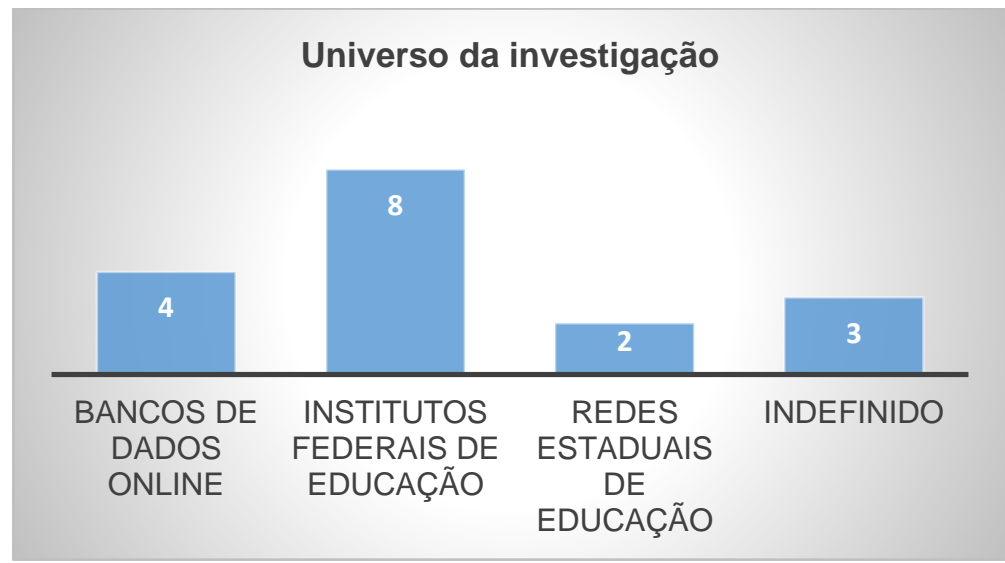

Fonte: Elaborado pelos autores. São Luís, 2019

Esse quantitativo expressivo, possivelmente, deve-se ao fato dos Institutos Federais serem "instituições de educação superior, básica e profissional, pluricurricular e multicampi, especializadas na oferta de educação profissional e tecnológica nas diferentes modalidades de ensino" (BRASIL, 2008), cuja Lei de criação, $n^{\circ} 11.892 / 08$, estabeleceu a obrigatoriedade de oferta de pelo ao menos $50 \%$ das vagas dos cursos de Educação Profissional na modalidade integrada ao Ensino Médio.

Após essa expressiva vantagem dos Institutos Federais, aparece na segunda posição, com quatro artigos, as pesquisas realizados em bancos de dados on-line, entre os quais encontram-se o Portal de Publicações do site da ANPEd, o Banco de Teses da CAPES, o Repositório OASIS-BR, o Google Acadêmico e o Banco de Dissertações e Teses dos Programas de Pós-Graduação em Educação da Universidade Federal de Minas Gerais e do CEFET-MG. Em menor número, aparecem as pesquisas realizadas nas Redes Estaduais de Educação do Estado do Paraná, com o total de dois artigos. E três dos artigos analisados, não especificam o universo de investigação da pesquisa.

Quanto à categoria de procedimentos técnico-metodológicos, faz-se necessário esclarecer que a soma do quantitativo expresso no Gráfico 3 é maior do que o número total de dezessete artigos analisados porque houve casos de um único artigo possuir mais de uma técnica de pesquisa. Utilizamos a classificação proposta por Gil (2002) para classificarmos os procedimentos teórico-metodológicos identificados nos artigos. 
Gráfico 3 - Procedimentos técnico-metodológicos

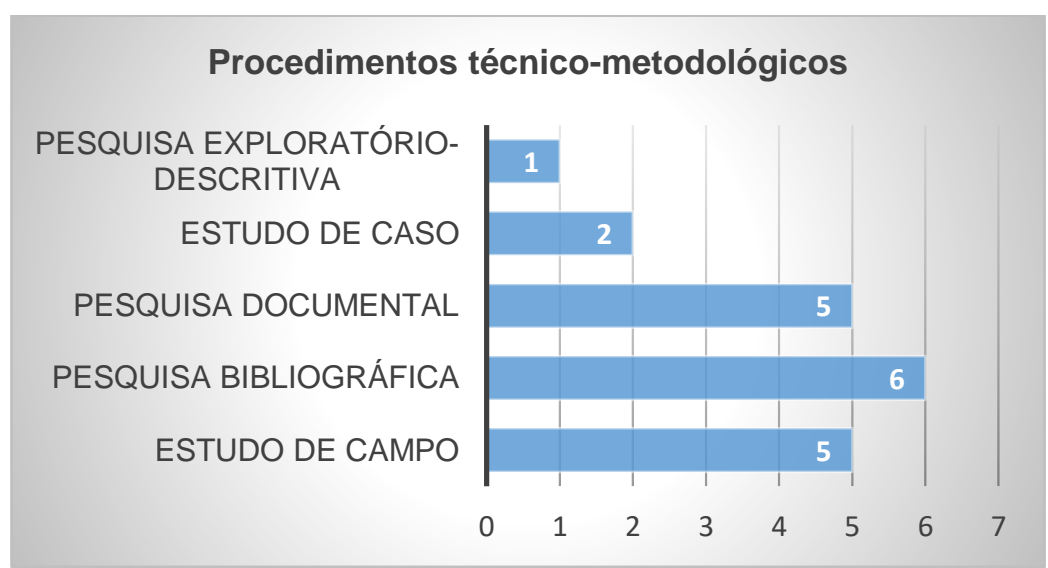

Fonte: Elaborado pelos autores. São Luís, 2019.

Conforme o Gráfico 3, a técnica de pesquisa mais utilizada foi a pesquisa bibliográfica, que aparece em seis artigos, seguida de perto pela pesquisa documental, com cinco artigos. Segundo Gil (2002), apesar de guardarem muitas semelhanças, a natureza das fontes marca a diferença essencial entre a pesquisa bibliográfica e a pesquisa documental. Enquanto a bibliográfica se caracteriza por utilizar prioritariamente as contribuições de diferentes autores sobre um assunto pré-determinado, a pesquisa documental "vale-se de materiais que não recebem ainda um tratamento analítico, ou que ainda podem ser reelaborados de acordo com os objetivos da pesquisa" (GIL, 2002, p. 45).

Empatado com a pesquisa documental aparece o estudo de campo, também com cinco artigos. Este estudo constitui-se num modelo clássico de investigação no campo das Ciências Sociais, sendo desenvolvido basicamente por meio de técnicas de observação direta e de entrevistas com membros do grupo estudado (GIL, 2002). Em menor quantidade aparecem o estudo de caso, com dois artigos e a pesquisa exploratória-descritiva com apenas um artigo.

A categoria seguinte refere-se ao ano de publicação dos artigos analisados. Pela análise do Gráfico 4 percebemos que a maioria dos artigos foram publicados nos anos de 2016 e 2017, com quatro publicações em cada ano. Em seguida, aparecem os anos de 2011, 2012 e 2015 com duas publicações cada. E os anos com menor número de publicações, apenas um artigo em cada, foram os de 2013, 2018 e 2019. Considerando que o intervalo de tempo de nossa pesquisa foi de dez anos, percebe-se que durante os anos 2009, 2010 e 2014 não houveram publicações sobre a temática em estudo.

Gráfico 4 - Anos de publicação



Fonte: Elaborado pelos autores. São Luís, 2019. 
Esta predominância de publicações nos anos de 2016 e 2017 coincide com o resultado encontrado no Mapeamento sobre o Ensino Médio Integrado (EMI) realizado por Bonfim et. al. (2019). Neste estudo, as autoras atribuíram a concentração das publicações no ano de 2017 à aprovação da Lei de Reforma do Ensino Médio, $n^{\circ}$ 13.415/2017, que coloca em risco o modelo de EMI como travessia para uma formação humana integral baseada no princípio educativo do trabalho, ao mesmo tempo que compromete o destino dos Institutos Federais de Educação.

A categoria seguinte de nossa análise é a da formação acadêmica dos autores dos artigos analisados.

Gráfico 5 - Formação acadêmica dos autores

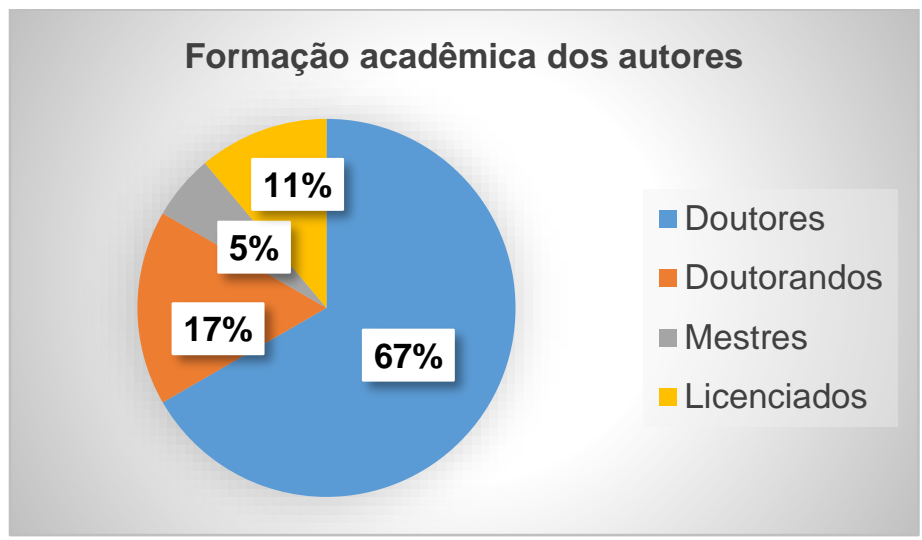

Fonte: Elaborado pelos autores. São Luís, 2019.

Conforme o Gráfico 5, a grande maioria das publicações são assinadas por Doutores (67\%) ou Doutorandos (17\%), dado que revela o interesse dos programas de pós-graduação pela temática do currículo integrado no âmbito da Educação Profissional, bem como o grande nível dos estudos nessa área. Nesse âmbito, a questão que se impõe é saber se está havendo continuidade nessas pesquisas (ou se elas se encerram com a diplomação de mestrado ou doutorado) e como elas de alguma forma repercutem nas discussões e propostas curriculares dos seus respectivos lócus de pesquisa.

Por fim, a última categoria de nossa análise diz respeito aos autores mais citados nos artigos analisados.

Gráfico 6 - Autores mais citados

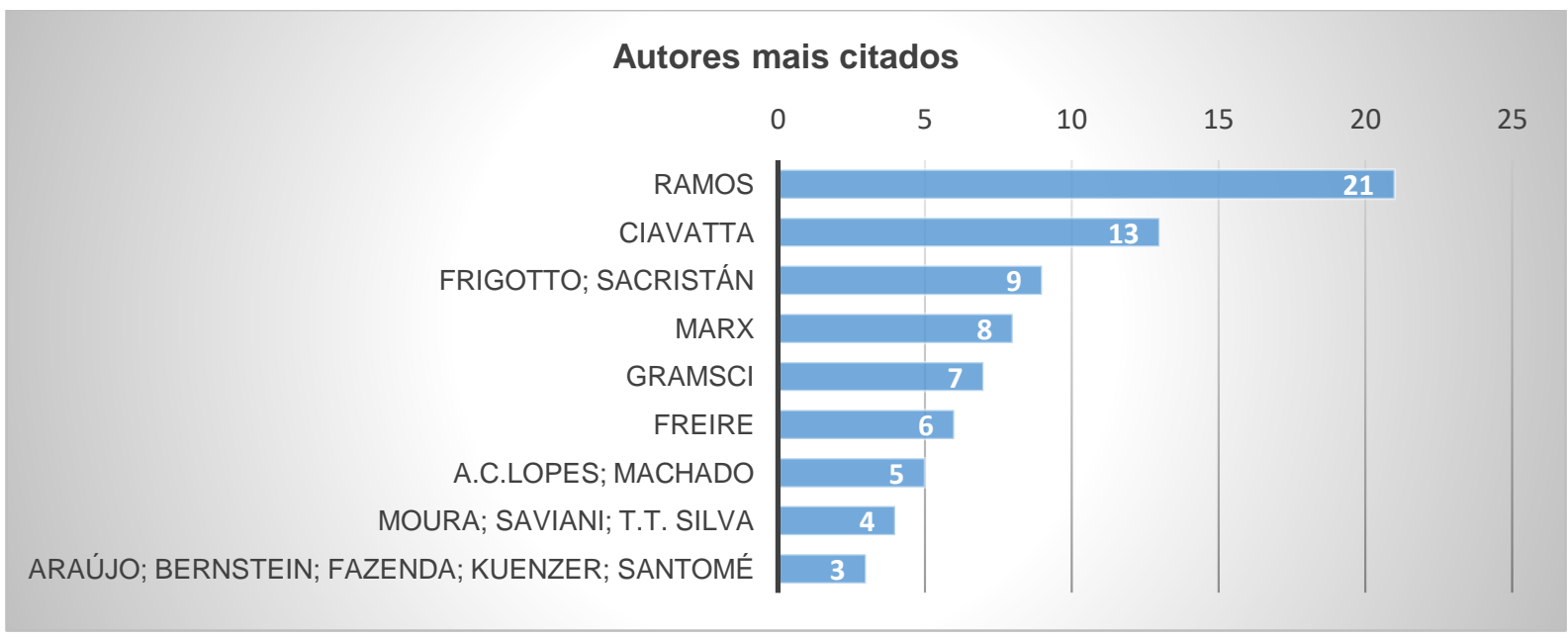

Fonte: Elaborado pelos autores. São Luís, 2019.

Conforme observa-se no Gráfico 6, a autora mais citada foi Marise Ramos, com vinte e uma referências, seguida por Maria Ciavatta com treze, e Gaudêncio Frigotto e Gimeno Sacristán empatados com nove referências cada. Estes são autores consagrados da área educacional e especialmente, dos 
estudos sobre currículo.

Logo em seguida, aparecem autores clássicos dos estudos sobre o trabalho como princípio educativo, base da concepção atual de Ensino Médio Integrado, como Karl Marx e Antonio Gramsci, com oito e sete citações, respectivamente; e Paulo Freire, idealizador de uma pedagogia que visa a emancipação dos sujeitos e a transformação social, com seis citações. Entre os autores mais citados, aparecem também Alice Lopes, Lucília Machado, Dante Moura, Tomás Tadeu da Silva, Dermeval Saviani, Ronaldo Araújo, Bernstein, Ivani Fazenda, Acácia Kuenzer e Santomé.

Após realizada a análise dos artigos encontrados no Mapeamento, na seção seguinte, apresentaremos as considerações finais, onde faremos uma síntese do trabalho de pesquisa realizado e concluiremos respondendo à questão central expressa no protocolo (Quadro 1) do nosso Mapeamento.

\section{CONSIDERAÇÕES FINAIS}

Entendido durante muito tempo simplesmente como um conjunto de técnicas e habilidades a serem dominadas, o currículo da Educação Profissional vem adquirindo uma nova concepção devido às mudanças da legislação educacional realizadas em meados dos anos 2000 e às lutas de educadores comprometidos com a construção de um ideal de formação humana integral.

Emerge nesse cenário, uma nova forma de fazer currículo que visa superar a histórica dicotomia entre formação básica e formação técnica, ou nas palavras de Ramos (2005, p. 106), "superar o histórico conflito existente em torno do papel da escola, de formar para a cidadania ou para o trabalho produtivo e, assim, o dilema de um currículo voltado para as humanidades ou para a ciência e tecnologia".

Denominada de currículo integrado, esta nova modalidade de organização curricular possibilita a superação da fragmentação do conhecimento, em prol de um ensino interdisciplinar e contextualizado essencial para a formação de cidadãos críticos, autônomos e emancipados.

Neste artigo, nos propomos a fazer um levantamento e análise das principais temáticas pesquisadas sobre o currículo integrado no âmbito da Educação Profissional nos últimos dez anos, utilizando, para isso, a metodologia do Mapeamento Sistemático. A partir deste resultado, somos agora capazes de enxergar para qual direção os estudos sobre essa temática estão apontando, se para a perspectiva da reprodução da ideologia dominante, expressa na concepção tradicional de currículo; ou para a construção de uma prática integradora que consegue articular os saberes, recompondo as partes num todo até então fragmentado.

Conforme os resultados identificados no Mapeamento, concluímos que os artigos analisados apontam para a direção da integração curricular, seja ela realizada em cursos técnicos integrados ao Ensino Médio na modalidade regular ou na modalidade da Educação de Jovens e Adultos. Outro aspecto importante a ser observado é a predominância das pesquisas realizadas em campis dos Institutos Federais de Educação, Ciência e Tecnologia, instituições voltadas para o desenvolvimento do ensino integrado baseado na articulação entre teoria e prática, tendo como base o princípio educativo do trabalho.

Concluímos ainda, que as formas de fazer currículo integrado são diversas, variando conforme as concepções dos sujeitos envolvidos no processo de construção dessa proposta, sejam eles gestores, professores e alunos. Diversas também, são as práticas pedagógicas integradoras mobilizadas para promover a aproximação entre teoria e prática na integração entre as diversas áreas do conhecimento. Assim como, muitos são os desafios que se apresentam a estes sujeitos para colocar em prática um currículo que atenda, ao mesmo tempo, as demandas do mundo do trabalho e as exigências de uma formação humana integral.

Conforme esclarece Amado (2015), estes embates são necessários, e através deles, podemos tanto intensificar como reduzir a propriedade crítica da proposta de currículo integrado. Uma vez reduzida, ela estaria igualada às concepções tradicionais de currículo, incorrendo no que Santomé (1998) denomina de mero slogan, ou apenas mais um instrumento a serviço da inculcação da ideologia dominante.

Sendo assim, pensamos que o importante é caminhar, mas sabendo para qual direção. O primeiro passo já foi dado, o de despertar o interesse dos sujeitos da prática educativa por uma forma de 
organização curricular que possibilite a formação de sujeitos autônomos, capazes de exercer a reflexão crítica, a participação ativa e o compromisso com os interesses sociais e coletivos. Esse é o potencial transformador do currículo integrado.

\section{REFERÊNCIAS}

AMADO, Luiz Antonio Saléh. O PROEJA e a proposta de integração curricular: dispositivos analisadores da educação. Trab. Educ. Saúde, Rio de Janeiro, v. 13, n. 2, p. 411-428, maio/ago. 2015.

AZEVEDO, M. A.; SILVA, C. D.; MEDEIROS, D. L. M. Educação Profissional e Currículo Integrado para o Ensino Médio: elementos necessários ao protagonismo juvenil. Holos, Ano 31, Vol. 4, pp. 77-88, 2015.

BRASIL. Decreto $\mathbf{n}^{\circ} \mathbf{5 . 1 5 4}$, de 23 de julho de 2004. Regulamenta o $\S 2^{\circ}$ do art. 36 e os arts. 39 a 41 da Lei $n^{\circ}$ 9.394, de 20 de dezembro de 1996, que estabelece as diretrizes e bases da educação nacional, e dá outras providências. Brasília, 2004. Disponível em:

http://portal.mec.gov.br/setec/arquivos/pdf1/proejadecreto5154.pdf. Acesso em: 23 abr. 2019.

BRASIL. Lei n $^{\circ}$ 11.892, de 29 de dezembro de 2008. Institui a Rede Federal de Educação Profissional, Científica e Tecnológica, cria os Institutos Federais de Educação, Ciência e Tecnologia, e dá outras providências. Diário Oficial da União, 29 de dezembro de 2008.

BONFIM, Cristiani Hembecker (et. al.). O Ensino Médio Integrado no contexto dos Institutos Federais de Educação: um Mapeamento Sistemático. Revista Labor, Fortaleza/CE, n² 21, Vol. 01, pp. 31-55, Jan./Jun. 2019.

CASTAMAN, Ana Sara; HANNECKER, Lenir Antonio. Currículo Integrado: pensando o Ensino Integrado nos Institutos Federais de Educação, Ciência e Tecnologia no Brasil. Educitec: Revista de Estudos e Pesquisas sobre Ensino Tecnológico, n. 05, 2017.

CIAVATTA, Maria. A Formação integrada: a escola e o trabalho como lugares de memória e de identidade. In: FRIGOTTO, Gaudêncio; CIAVATTA, Maria; RAMOS, Marise (Org.). Ensino Médio Integrado: concepções e contradições. São Paulo: Cortez, 2005.

ESTIVALETE, Emerson Bianchini. A crescente preocupação com a integração de saberes através do currículo. Educação Por Escrito, Porto Alegre, v. 7, n. 1, p. 34-46, jan.-jun. 2016.

FAZENDA, Ivani. Integração ou Interdisciplinaridade no Ensino Brasileiro. Efetividade ou Ideologia. Ed. Loyola, 6a ed. São Paulo: Brasil, 2011.

FRIGOTTO, Gaudêncio; CIAVATTA, Maria; RAMOS, Marise (Org.). Ensino Médio Integrado: concepções e contradições. São Paulo: Cortez, 2005.

GIL, Antonio Carlos. Como elaborar Projetos de Pesquisa. $4^{\mathrm{a}}$ ed. São Paulo: Atlas, 2002.

MARX, Karl. O capital. Rio de Janeiro: Bertrand, 1994.

MIRANDA, Paula Reis de; FONSECA, Maria da Conceição Ferreira Reis. Estudantes do PROEJA e o currículo de Matemática: tensões entre discursos numa proposta de integração. Educação Matemática em Pesquisa, São Paulo, v.19, n.3, pp.131-156, 2017.

MOREIRA, Nara; GOBBI, Gianna Andréia Ferreira. Educação Profissional Técnica Integrada ao Ensino Médio: desafios da implantação de uma proposta de currículo integrado no IFTM - Campus Paracatu. Revista Pedagógica - UNOCHAPECÓ - Ano-14 - n. 27 vol. 02 - jul./dez. 2011.

MOURA, Dante Henrique. Educação básica e educação profissional e tecnológica: Dualidade histórica e perspectivas de integração. Holos, v. 2, p. 4-30. Natal, 2007.

PEDROSA, Eliane Maria Pinto. Concepções do ensinar Ciências da Natureza e Matemática no currículo integrado do PROEJA. Revista Educação e Emancipação, São Luís, v. 9, n. 3, ed. especial, jul./dez. 2016.

RAMOS, Marise. Possibilidades e desafios na organização do currículo integrado. In: FRIGOTTO, Gaudêncio; CIAVATTA, Maria; RAMOS, Marise (Orgs.). Ensino médio integrado: concepção e 
contradições. São Paulo: Cortez, 2005.

ROCHA, Fábio Gomes; NASCIMENTO, Bruno Alves Reis; NASCIMENTO, Ester Fraga Vilas-Bôas Carvalho do. Um modelo de mapeamento sistemático para a educação. Cadernos da Fucamp, v.17, n.29, p. 1-6, 2018.

RODRIGUES, Denise Dálmas; ARAÚJO, Maria Cristina Pansera de. A integração curricular na concepção dos docentes do Curso Técnico em Agropecuária integrado ao Ensino Médio. Revista Góndola, Enseñanza y Aprendizaje de las Ciencias, Bogotá, Colômbia, v. 12, n. 1, ene-jun 2017.

SACRISTÁN, José Gimeno. O Currículo: uma reflexão sobre a prática. Trad. Ernani F. da F. Rosa. 3 ed. Porto Alegre: ArtMed, 2000.

SALES, Márcia Castilho de; REIS, Renato Hilário dos. As perspectivas de integração no currículo da Educação Profissional integrada à EJA. Espaço do Currículo, João Pessoa, v.12, n.1, p. 153-170, jan./abr. 2019.

SANTOMÉ, Jurgo Torres. Globalização e Interdisciplinariedade: o currículo integrado. Trad. Cláudia Schilling. Porto Alegre: ArtMed, 1998.

SANTOS, F. A. A.; SANTOS, J. D.; PROFESSOR, V. P.; SILVA, A. R. Práticas pedagógicas integradoras no Ensino Médio Integrado. Holos, Ano 34, Vol. 06, 2018.

SANTOS, Fernanda Pereira; NUNES, Célia Maria Fernandes; VIANA, Marger da Conceição Ventura Viana. Currículo, interdisciplinaridade e contextualização na disciplina de Matemática. Educação Matemática em Pesquisa, São Paulo, v.19, n.3, pp.157-181, 2017.

SANTOS, Tiago Borges dos. Integrando saberes: reflexão sobre o currículo integrado da Educação Profissional Técnica de nível médio no Instituto Federal de Brasília. Eixo, v. 1, n. 1, 2012.

SAVIANI, Nereide. Saber escolar, currículo e didática: problemas da unidade conteúdo/método no processo pedagógico. $2^{\mathrm{a}}$ ed. Campinas, SP: Autores Associados, 1998.

SILVA, J. M. N.; SÁ, A. L. T. F. O PROEJA no IFRN - Campus Mossoró por seus estudantes. Holos, Ano 32, Vol. 7, 2016.

SILVA, Maria Aparecida da. Currículo de Educação Profissional integrada à EJA: uma pesquisa em parceria. Espaço do Currículo, João Pessoa, v.6, n.3, p.447-461, set./dez. 2013.

SILVA, Mônica Ribeiro da. A política de integração curricular no âmbito do PROEJA: entre discursos, sujeitos e práticas. Ensaio: aval. pol. públ. Educ., Rio de Janeiro, v. 19, n. 71, p. 307-326, abr./jun. 2011.

VIRIATO, Edaguimar Orquizas; FAVORETO, Aparecida; KLEIN, Lígia Regina. Trabalho docente, PROEJA e Currículo Integrado: algumas reflexões. Perspectiva, Florianópolis, v. 30, n. 2, 719-744, maio/ago. 2012.

ZATTI, Vicente. Institutos Federais de Educação: um novo paradigma em Educação Profissional e Tecnológica? Revista Ibero-Americana de Estudos em Educação, v. 11, n. 3, p.1461-1480, 2016.

Este obra está licenciado com uma Licença Creative Commons Atribuição-NãoComercial 4.0 Internacional. 